\title{
Venous Sinus
}

National Cancer Institute

\section{Source}

National Cancer Institute. Venous Sinus. NCI Thesaurus. Code C12877.

A large vein or channel for the circulation of venous blood, such as one of the sinuses of the dura mater. 